\title{
Peripheral Giant Cell Granuloma: A Case Report with Review on Its Histogenesis and Recurrence
}

\author{
Deepti Garg Jindal ${ }^{1}$ Sandhya Singh Kushwaha \\ ${ }^{1}$ Department of Oral Pathology \& Microbiology, Bhojia Dental \\ College \& Hospital, Baddi, Himachal Pradesh, India \\ 2Department of Conservative Dentistry \& Endodontics, Bhojia \\ Dental College \& Hospital, Baddi, Himachal Pradesh, India \\ ${ }^{3}$ Department of Oral Pathology \& Microbiology, Maharaja \\ Ganga Singh Dental College and Research Centre, Ganganagar, \\ Rajasthan, India
}

Sonia Joshi ${ }^{1}$ Namita Sepolia ${ }^{1}$ Varun Jindal ${ }^{2} \quad$ Kanu Jain ${ }^{3}$

Dent J Adv Stud 2019;7:95-98

\begin{abstract}
Address for correspondence Deepti Garg Jindal, MDS, Department of Oral Pathology \& Microbiology, Bhojia Dental College \& Hospital, Baddi 176052, Himachal Pradesh, India (e-mail: drdeeptigarg08@gmail.com).
\end{abstract}

\begin{abstract}
Keywords

- Granuloma

- histogenesis

- multinucleated giant cells

- peripheral

- recurrence

Giant cell granulomas (GCGs) of the jaws are non-neoplastic lesions that arise either peripherally in periodontal ligament, mucoperiosteum, or centrally in the bone. Histologically, both peripheral and central giant cell granuloma are characterized by the presence of numerous multinucleated giant cells in a prominent fibrous stroma. Peripheral giant cell granuloma is an infrequent reactive, exophytic lesion of the oral cavity, also known as giant-cell epulis, osteoclastoma, giant cell reparative granuloma, or giant cell hyperplasia. It is the most common giant cell lesion of the jaws and originates from the connective tissue of the periosteum or from the periodontal membrane, in response to local irritation or chronic trauma. The lesion develops mostly in adults, commonly in the lower jaw, with slight female predilection although is uncommon in children. Clinically, it shows resemblance to pyogenic granuloma, peripheral ossifying fibroma, and many other peripheral lesions seen in the oral cavity, but in our case it resembled a squamous cell carcinoma, thereby histopathology is mandatory for the diagnosis of this lesion. The lesion although being relatively common, still has a lot of ambiguity. The ambiguity is in terms of its etiology, growth potential, biological behavior (recurrence), histogenesis of its cells, and its treatment. The entity further holds significance because of its notorious behavior and high tendency to recur. This is a case report of a 30-year-old female patient with history of swelling in the lower anterior region of jaw since 1 year. After complete excision of lesion, lesion reoccurred after few months.
\end{abstract}

\section{Introduction}

Multinucleated giant cells (MNCs) are important structural components of various tumors, tumorlike lesions, and granulomas of immunologic and nonimmunologic origin. ${ }^{1,2}$ The presence and absence of various types of giant cells are different in different lesions, and its significance depends on the lesion in which they are present. MNCs represent highly stimulated cells of macrophages lineage at a terminal stage of maturation and are also known for its phagocytic activity in response to hemorrhage in chronic reparative granulation tissue. ${ }^{3}$

received

August 24, 2018

accepted after revision

February 27, 2019

published online

May 27, 2019
The name "giant-cell reparative granuloma" occurring in the jaws was first given by Jaffe in 1953 whereas in 1954 Bernier and Cahn named "peripheral giant cell reparative granuloma" for the lesions that do not occur centrally within the bone. ${ }^{4.5}$ It is considered as the most common reactive lesion occurring on the gingiva or alveolar mucosa. ${ }^{6-8}$ It commonly appears as a painless well-defined, reddish-purple, sessile, or pedunculated growth that arises from the gingival mucosa, and sometimes, it can be secondarily infected and ulcerated. Peripheral giant cell granulomas (PGCGs) seldomly exceed $2 \mathrm{~cm}$ in greatest diameter. PGCGs are often due to various local contributing factors, such as food impaction, extractions, faulty dental restorations,

C2019 Bhojia Dental College and Hospital affiliated to Himachal

Pradesh University
License terms

(1) (1) $\odot \circledast$ 10.1055/s-0039-1688548

ISSN 2321-1482. 
ill-fitting dentures, and calculus. The most common age of occurrence is fourth and sixth decades. It is predominantly seen in women (2:1). It primarily affects posterior mandibular alveolar mucosa. ${ }^{9}$ The origin of PGCG is mostly from the lamina propria of the gingival tissue, periodontal ligament membrane, and/or periosteum of the alveolar bony ridge. The term peripheral giant cell granuloma is preferred because of the lack of the reparative response in such lesions. ${ }^{4,5,9}$

\section{Case Presentation}

A 30-year-old female patient reported to the department of oral pathology with the complaint of a growth in the lower front region of the jaw since 1 year. The patient noticed the swelling 1 year ago, which was smaller in size and gradually increased to the present size. The patient did not give any history of pain, trauma, and infection. The family and medical history was not significant. The oral hygiene of the patient was very poor. Intraorally painless growth was present on the lingual mandibular gingiva with respect to $31,32,33,41,42$, and 43 since 1 year measuring $2 \times 4 \mathrm{~cm}$ in diameter with ulceration ( - Fig. 1). Angular cheilitis was also seen. The patient had history of poor oral hygiene with

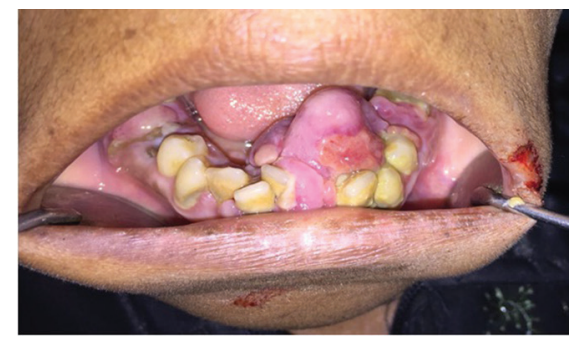

Fig. 1 Intraorally painless growth was present on the lingual mandibular gingiva with respect to $31,32,33,41,42,43$ since 1 year measuring $2 \times 4 \mathrm{~cm}$ in diameter with ulceration on the growth.

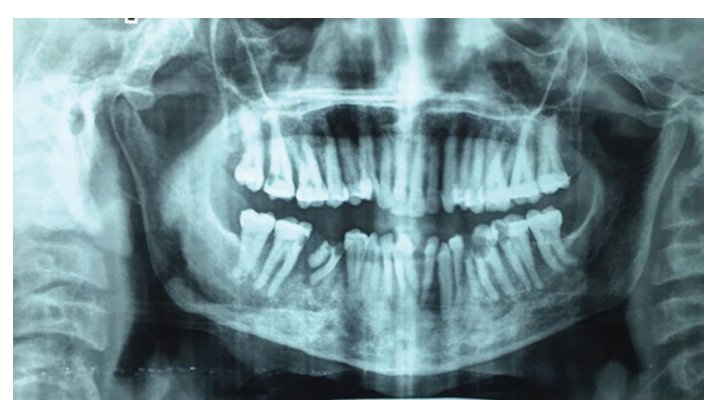

Fig. 2 Radiographic examination revealing radiolucency with respect to 31 and 32 and root stumps with respect to 46 .

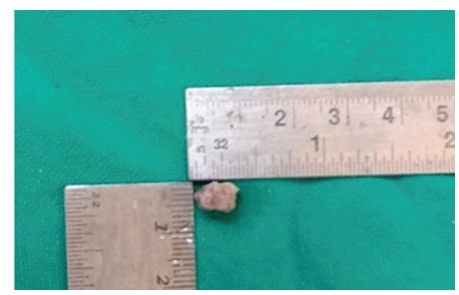

Fig. 3 Gross specimen showing sample measuring $1 \times 0.6 \times 0.4 \mathrm{~cm}$, irregular in shape, dirty white in color, smooth in surface, and firm in consistency.

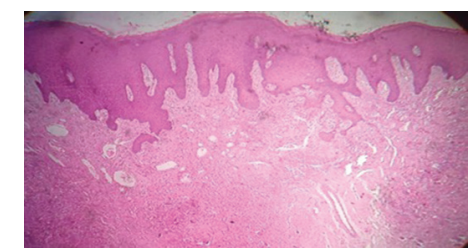

Fig. 4 Scanner view (4×) showing epithelium and connective tissue.

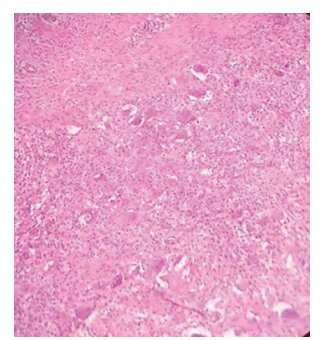

Fig. 5 Connective tissue showing dense collagen fibers, numerous multinucleated giant cells, fibroblasts, blood vessels (40×).

calculus deposition, especially on the lingual mandibular incisor region. Radiographic examination revealed radiolucency with irregular borders in relation to 31 and 32, and root stumps were present with respect to 46 ( - Fig. 2). Based on the clinical examination and detailed history, the patient was convinced for the biopsy to rule out the other differential diagnoses such as pyogenic granuloma (PG), peripheral odontogenic fibroma, peripheral ossifying fibroma, peripheral giant cell granuloma, and squamous cell carcinoma. Macroscopically, the tissue was approximately $1 \times 0.6 \times 0.4$ $\mathrm{cm}$ in size, irregular in shape, dirty white in color, smooth in surface, and firm in consistency ( - Fig. 3). Microscopic examination showed stratified squamous epithelium of parakeratinized type with underlying connective tissue. The connective tissue showed dense collagen fibers, numerous MNCs, fibroblasts, blood vessels, and calcification areas ( - Figs. 4, 5). The characteristic presence of MNCs in the connective tissue leads us to the final diagnosis of PGCG. During the follow-up, the patient again reported with the reoccurrence of the lesion within 1 month. The excisional biopsy of the lesion was done, and the sample was submitted for histopathologic examination that again confirmed the diagnosis of reoccurred PGCG.

\section{Discussion}

PGCG originates from the interdental tissues, that is, the periosteum or periodontal membrane. ${ }^{10,11}$ Gingival or alveolar mucosa are the most commonly involved, preferably anterior to the molar teeth. ${ }^{8}$ There is a wide age range for such lesions, although the peak incidence in males is in the second decade compared with the fifth decade for females. ${ }^{12}$ It shows slight female predilection (2:1), and the mandible is more commonly involved than the maxilla. ${ }^{13}$ The etiology of PGCG is still not clear, but various local irritating factors, such as chronic irritants, tooth extractions, xerostomia, hormonal influence, etc., may contribute in the formation of the lesion. 
1. Chronic irritants: PGCG is considered to be a reactive lesion due to local irritation or trauma (Sood et al). The predisposing factors may include trauma, faulty restorations, plaque, calculus, chronic infections, and impacted food. ${ }^{14}$

2. Tooth extractions: PGCG may show reoccurrence after extraction of teeth. Some authors suggested that a healing socket must be rich in growth factors and therefore stimulate the growth of PGCG and eventual lesion development. ${ }^{15}$

3. Xerostomia: Some authors reported a significantly higher percentage of large PGCGs $(>2 \mathrm{~cm})$ in people with xerostomia. ${ }^{16}$

4. Hormonal influence: Some authors suggested that the lesion was not always hormone dependent, but it may be due to immunosuppressive action of hormones along with hyperresponsiveness of the gingiva to these hormones. ${ }^{17}$

5. Mighell et al 1995 stated that PGCG can occur in the edentulous area with the absence of periodontal membrane and local irritants. It gave an idea that either the cells of attached gingiva or alveolar mucosa have the potential to form PGCG in dentate and edentulous states. ${ }^{15}$

Flaitz suggested that PGCG can arise secondarily to an alteration of the endothelial cells of the capillaries. ${ }^{10}$ Adlakha et al considered endothelial cells of the capillaries to have phagocytic response to hemorrhage in a preexisting granulation tissue, which results in the formation of PGCG. ${ }^{18}$ Souza et al described in their study that Ki67 (proliferative marker) is expressed through G1, S, G2, and M phase of the cell cycle, and its demonstration indicates proliferative stage of these cells and Ki67-positive cells were seen largely in PGCG. ${ }^{19}$

Clinically, it has been found that the incidence rate of PGCG among all oral reactive lesions varies from 5.1 to $43.6 \%$. The age incidence of PGCG is most common in the fourth (40\%) to sixth decade of life. PGCG has female predilection (65\%), same as in our case. PGCG involves the mandible (55\%) more than the maxilla (2.4:1), same as seen in our case. Clinical characteristic features of PGCG show an asymptomatic, soft, nodular mass with red to reddish-blue color. However, repeated trauma due to occlusion can lead to ulceration and secondary infection. Seldomly, the lesion is painful. A secondarily infected lesion presents a "yellow zone" caused by the aggregation of a fibrin clot at the ulcer site. It is usually not more than $1.5 \mathrm{~cm}$ in diameter. Radiographically, superficial bone resorption, widening of the periodontal ligament space, and mobility of associated teeth are usually seen. When the lesion involves edentulous areas, the cortical bone exhibits a concave resorption beneath the lesion. This typical feature is known as "leveling" effect. This feature is also referred to as "cupping" resorption by many authors. ${ }^{15}$

PGCG shows the same clinical features as of PG, central giant cell granuloma, peripheral ossifying fibroma, and metastatic carcinomas. ${ }^{20}$ Microscopic examination shows the presence of hyperplastic parakeratinized stratified squamous epithelium. The connective tissue shows the presence of numerous young proliferating fibroblasts in vascularized fibrocellular stroma with numerous blood capillaries and abundant MNCs. ${ }^{18}$
The treatment of PGCG comprises surgical resection with elimination of the entire base of the lesion along with removal of the underlying irritant factors. ${ }^{10,11,21}$ To avoid recurrence after treatment, extensive clearing of the lesion base and the source of irritation should be eliminated after complete excision of the lesion. ${ }^{8}$

Recurrence of PGCG is quite uncommon and ranges between 5 and $11 \%$, as reported. ${ }^{15}$ PGCGs that contain calcifications appear more likely to recur.

\section{Conclusion}

PGCG is a benign, reactive lesion occurring on the gingiva around teeth as well as in edentulous areas. This case report of PGCG has higher recurrence rate compared with previously published studies as the patient underwent complete excision twice within 1 month. Therefore, more cases should be reported for such kind of ambiguous reactive lesions.

\section{Conflict of Interest}

None declared.

\section{References}

1 Chambers TJ. Multinucleate giant cells. J Pathol 1978; 126(3):125-148

2 Creighton C. An infective form of tuberculosis in man identical with Bovin tuberculosis. Virchows Arch 1858;14:177-216

3 Doussis IA, Puddle B, Athanasou NA. Immunophenotype of multinucleated and mononuclear cells in giant cell lesions of bone and soft tissue. J Clin Pathol 1992;45(5):398-404

4 Jaffe HL. Giant-cell reparative granuloma, traumatic bone cyst, and fibrous (fibro-oseous) dysplasia of the jawbones. Oral Surg Oral Med Oral Pathol 1953;6(1):159-175

5 Bernier JL, Cahn LR. The peripheral giant cell reparative granuloma. J Am Dent Assoc 1954;49(2):141-148

6 Neville BW. Soft tissue tumors. In: Neville BW, Damm D, Bouquot JW, eds. Oral and Maxillofacial Pathology. Philadelphia, PA: Elsevier Sunders; 2002:437-479

7 Katsikeris N, Kakarantza-Angelopoulou E, Angelopoulos AP. Peripheral giant cell granuloma. Clinicopathologic study of 224 new cases and review of 956 reported cases. Int J Oral Maxillofac Surg 1988;17(2):94-99

8 Kfir Y, Buchner A, Hansen LS. Reactive lesions of the gingiva. A clinicopathological study of 741 cases. J Periodontol 1980;51(11):655-661

9 Pirih F, Barroso AD, Tatarakis N, Cordell K, McCauley L, Edwards P. A case report of a peripheral giant cell granuloma in a patient on Forteo. 2015;22(3)

10 Flaitz CM. Peripheral giant cell granuloma: a potentially aggressive lesion in children. Pediatr Dent 2000;22(3):232-233

11 Katsikeris N, Kakarantza-Angelopoulou E, Angelopoulos AP. Peripheral giant cell granuloma. Clinicopathologic study of 224 new cases and review of 956 reported cases. Int J Oral Maxillofac Surg 1988;17(2):94-99

12 Soames JV, Southam JC. Hyperplastic, neoplastic and related disorders of oral mucosa. In: Soames JV, ed. Textbook of Oral Pathology. 4th ed. Oxford, UK: Oxford Medical Publications; 2000:103

13 Nedir R, Lombardi T, Samson J. Recurrent peripheral giant cell granuloma associated with cervical resorption. J Periodontol 1997;68(4):381-384 
14 Sood S, Gulati A, Yadav R, Gupta S. Peripheral giant cell granuloma-a review. Indian J Multidiscip Dent 2012;2 (2):435-440

15 Mighell AJ, Robinson PA, Hume WJ. Peripheral giant cell granuloma: a clinical study of 77 cases from 62 patients, and literature review. Oral Dis 1995;1(1):12-19

16 Bodner L, Peist M, Gatot A, Fliss DM. Growth potential of peripheral giant cell granuloma. Oral Surg Oral Med Oral Pathol Oral Radiol Endod 1997;83(5):548-551

17 Shirani G, Arshad M. Relationship between circulating levels of sex hormones and peripheral giant cell granuloma. Acta Med Iran 2008;46:429-433
18 Adlakha VK, Chandna P, Rehani U, Rana V, Malik P. Peripheral giant cell granuloma. J Indian Soc Pedod Prev Dent 2010;28(4):293-296

19 Souza PE, Mesquita RA, Gomez RS. Evaluation of p53, PCNA, Ki-67, MDM2 and AgNOR in oral peripheral and central giant cell lesions. Oral Dis 2000;6(1):35-39

20 Pandolfi PJ, Felefli S, Flaitz CM, Johnson JV. An aggressive peripheral giant cell granuloma in a child. J Clin Pediatr Dent 1999;23(4):353-355

21 Patil KP, Kalel KP, Kanakdande VD. Peripheral giant cell granuloma: a comprehensive review of an ambiguous lesion. Journal of ICDRO 2014;6(2):118-125 